Revista Educação e Políticas em Debate - v. 7, n. 1, p. 132 - 150 - jan./abr. 2018 - ISSN 2238-8346

\title{
Fechar escolas no campo: uma manifestação da vulnerabilidade do direito à educação do campo no Semiárido Brasileiro
}

\author{
Closing schools in the field: a manifestation of the vulnerability of the right to the education of the \\ field in the Brazilian Semi-ariad
}

Clôture des écoles sur le terrain: manifestation de la vulnérabilité du droit à l'éducation du terrain dans le semi-orient brésilien

Edmerson dos Santos Reis ${ }^{1}$

Universidade do Estado da Bahia

Ádma Hermenegildo Rocha ${ }^{2}$

Universidade do Estado da Bahia

Resumo: Revelar o desrespeito ao direito à Educação do Campo no Semiárido Brasileiro é a intenção das reflexões deste artigo. Essa perspectiva é baseada em pesquisa realizadajunto ao censo escolar 2014, efetivadopelo Instituto Nacional de Estudos e Pesquisas Educacionais Anísio Teixeira nos municípios brasileiros. O objeto de estudo foi o fechamento de escolas do campo no Semiárido Brasileiro, nos municípios do Território do Sertão do São Francisco, localizado no norte da Bahia. Conclui-se que o poder público, materializado pelas Secretarias Estaduais e Municipais de Educação, coloca em vulnerabilidade o direito à Educação quando fecha escolas do campo sem ouvir a comunidade e sob o argumento de que os custos determinam a continuidade e a existência da escola nas comunidades do campo.

Palavras-chave: Educação do Campo. Semiárido. Direito à Educação.

Abstract: To reveal the disrespect to the right to Field Education in the Brazilian Semi-Arid is the intention of the reflections of this article. This perspective is based on research carried out with the 2014 school census, carried out by the National Institute of Studies and Educational Research Anísio Teixeira in the Brazilian municipalities. The object of study was the closure of rural schools in the Brazilian Semi-arid, in the municipalities of the Sertão do São Francisco Territory, located in the north of Bahia. It is concluded that the public power, materialized by the State and Municipal Secretariats of Education, places the right to Education in vulnerability when it closes schools in the countryside without listening to the community and on the grounds that costs determine the continuity and existence of the school in the communities of the countryside.

Key words: Field Education. Semi-arid. Right to education.

\footnotetext{
${ }^{1}$ Doutor em Educação. Professor Adjunto do Departamento de Ciências Humanas- DCH/III e do Programa de Pós-graduação Mestrado em Educação, Cultura e Territórios Semiáridos - PPGESA; Coordenador do Grupo de Pesquisa em Educação Contextualizada, Cultura e Território - EDUCERE/UNEB. Membro da Rede de Educação do Semiárido Brasileiro - RESAB e do Fórum Nacional de Educação do Campo - FONEC. E-mail. edmerson.uneb@gmail.com

${ }^{2}$ Mestranda do Programa de Pós-graduação - Mestrado em Educação, Cultura e Territórios Semiáridos PPGESA. Membro voluntário do Projeto de Pesquisa e Extensão Reflexão dos Referenciais da Educação Contextualizada e do Grupo EDUCERE.E-mail. admarocha_@hotmail.com
} 
Résumé: Révéler le manque de respect au droit à l'éducation sur le terrain dans le semiaridebrésilienestl'intention des réflexions de cet article. Cette perspective estbasée sur unerechercheréalisée avec le recensementscolaire 2014, réalisée par l'Institut national d'études et de recherchespédagogiquesAnísio Teixeira dans les municipalitésbrésiliennes. L'objet de l'étudeétaitlafermeture d'écolesruralesdanslesemi-aridebrésilien, danslesmunicipalitésduterritoire de Sertão do São Francisco, situédanslenord de Bahia. Onenconclut que lepouvoirpublic, matérialisé par lessecrétariats d'État et municipaux de l'éducation, placeledroit à l'éducationdanslavulnérabilitélorsqu'ilfermelesécoles à lacampagnesansécouterlacommunauté et que lescoûtsdéterminentlacontinuité et l'existence de l'école. communautés de lacampagne.

Mots-clés: Éducation de terrain. Semi-aride. Droit à l'éducation.

Recebido em: 20 de julho de 2018

Aceito em: 31 de outubro de 2018

\section{Introdução}

Discutir o fenômento do fechamento de escolas do Campo no Semiárido Brasileiro (SAB), partindo da premissa de que a extinção dessas escolas se concretiza como uma violação aos direitos básicos de qualquer cidadão, é a intenção do presente artigo, pois como está previsto na Constituição Federal (1988), em seu art.205, “a Educação é um direito de todos, e dever do Estado e da família a promoção e garantia desta”, além de ser um direito subjetivo previsto em outros marcos legais brasileiros.

Partindo desse princípio de direitos, e da garantia destes por parte do Estado no que diz respeito à construção de instituições escolares e manutenção destas, o mesmo tem como dever ofertar um ensino gratuito e de qualidade a toda a população, situação que torna-se contraditória quando voltamos nossos olhares para o Semiárido Brasileiro, que sempre foi posto a margens da desvalorização e marginalização, por parte dos “grandes” governantes, que preferiram e continuam preferindo usar a óptica da invisibilidade, tratando a população, e a própria Região de forma estereótipada, onde a negação dos direitos torna-se bem mais fácil e relevante quando o interesse e o poder caminham por uma outra vertente.

Dessa forma, é nesse caminhar e nessas reflexões acerca de direitos, garantia e negação desses, que esse artigo pretende trilhar seu caminho, haja vista que o real objetivo é dar visibilidade a uma discussão ainda pouco debatida e divulgada nas grandes mídias, atentando para o fato de que, o fechamento de escolas do campo é muito mais do que um alarmante número de dados quantitativos;é acima de tudo, uma violação aos direitos básicos da população 
campesina - o direito à Educação -, e não qualquer educação, qualquer "sobra", qualquer “adaptação" dos currículos urbanos, mas uma educação de qualidade, que forme integralmente crianças/jovens e adultos do campo como cidadãos históricos e senhores da sua história, tendo como fundamento da formação os saberes das suas culturas e do trabalho que constitui o campo.

É válido ressaltar que quando levantamos a bandeira contra o fechamento de escolas do campo, não estamos, de forma alguma, negligenciando o aprendizado que essas pessoas, crianças/jovens e adultos, formadoras da população campesina trazem consigo ao longo de suas vidas. Logo, estamos cientes de que a escola não é a única fonte de conhecimento, pois nós, seres humanos, aprendemos o tempo inteiro, justamente por vivermos em constante processo de interação entre objetos e pessoas; por isso não podemos camuflar o aprendizado que são apreendidos fora do ambiente escolar, onde esses deveriam servir de fonte de formação dos processos educativos presentes na escola.

O direito à Educação, previsto na Constituição Brasileira de 1988 e em todos os marcos legais posteriores à mesma, não pode continuar sendo negado à população campesina. $\mathrm{O}$ acesso à escola nas comunidades campesinas precisa continuar sendo uma pauta presente na agenda de luta das comunidades por uma Educação igualitária e contextualizada à vida, ao trabalho e à cultura desses povos, mesmo sabendo que, na mioria das vezes, a escola no seu formato tradicional ainda concentra suas forças e metodologias em conhecimentos que não levam em consideração a realidade dos sujeitos, o que tem sido uma busca dos movimentos pela reversão desta situação.

Por isso, partimos do pressuposto legal de que ter acesso a escola é um direito! Por que negá-lo? Por que é mais fácil fechar a escola, do que reorganizá-la? Por que negar? Negar educação de qualidade às crianças do campo, tornando-as ativas no processo de apredizagem, negar escola com infraestrutura adequada, negar a realidade das crianças/ jovens e adultos, negar uma formação crítica e contextualizada à população do Campo Semiárido, por quê? Os questionamentos que inspiram esta escrita e a tentativa de compreender as possíveis respostas são os fundamentos que nos movem na construção enganjada, acadêmica e denunciante do presente tex to ao entendermos que, ao fechar uma escola do campo, sem ouvir a comunidade e com ela decidir à respeito, o Estado estádesconsiderando todas as implicações que esta medida pode trazer para os estudantes, familiares e comunidade já que de maneira arbitrária, na maioria das vezes, fecha a escola e transporta os estudantes para outras comunidades e 
mesmo para a sede dos municípios, promovendo o desenraizamento do seu território eda sua cultura.

\section{Metodologia}

Esse artigo surge das muitas inquietações iniciadas desde o ano de 2015, quando realizamos uma pesquisa que perpassou por um caminho metodológico que utilizou, primeiramente, a pesquisa documental, por meio da planilha divulgada pelo Movimento Sem Terra - MST (2015), e a Cartilha da Nova Delimitação do Semiárido Brasileiro (2005), quando fizemos o mapeamento da quantidade de escolas do campo extintas no ano de 2014, e com esses dados, tivemos a oportunidade de discutir sobre o direito a Educação do Campo, tendo como conceitos chaves, a Região do Semiárido Brasileiro, o Campo, a Educação Contextualizada, e o direito à Educação, fazendo uso de autores como Reis (2011); Martins (2011); Resolução nº2/2008, Censo Escolar (2014),entre outros autores e marcos legais.

Para tanto, como continuação da discussão iniciada no ano de 2015, resolvemos utilizar alguns dos conceitos acima mencionados, bem como outras fontes biblográficas, para ampliarmos a discussão da garantia do direito à Educação à população campesina, quandoalém da pesquisa documental, fizemos uso da pesquisa bibliográfica que, como aponta Gil (2002), é caracterizada por estudos de trabalhos já publicados, como livros, artigos científicos, revista e outras fontes seguras de informação.

Nesta perspectiva, no caminho metodológico dessa produção fizemos um estudo apenas bibliográfico acerca dos conceitos chaves acima mencionados, enfatizando a educação como um direito previsto na legislação, que deve ser garantido à toda a população, independentemente de onde estejalocalizada.

\section{Fundamentação teórica}

Como este artigo centra-se em discutir sobre o direito à Educação do Campo, no recorte do Semiárido Brasieliro, é imprescindível falar sobre essa Região, desconstruir estereótipos que insistem em existir sobre a realidade do povo que a compõe, estereótipos esses que marcam a vida da população do Semiárido, assim como contribui para muitas desigualdades sociais ainda presentes no cotidiano dessas pessoas. Por isso mesmo, esse é o momento de se despir 
de todo preconceito, e visão redundante, esqueçam imagens de seca, chão rachado, crianças com fome e doentes, e reflitam: "o que é o Semiárido e o que o compõe?”

Para muitos, dentro de um imáginário social construído a partir de estereótipos, o Semiárido é somente uma região que falta tudo, água, alimentação, educação, segurança, saúde, políticas públicas, entre outras coisas que a cidade tem, mas o campo não. Afinal de contas, o Semiárido é composto somente pela zona rural dos municípios? As pessoas são sempre tristes como as imagens que os livros didáticos demonstram? Que preconceitos são esses que insistem em existir, mesmo com o passar dos anos? Que realidade é essa que não nos representa? Por que toda essa indiferença?

Desmistifificando um pouco dessas questões, Baptista e Campos (2013, p.29) nos essclarecem o seguinte:

essa realidade do Semiárido, propagada e consolidada no imaginário social, não é resultado de calamidades originadas no clima e na manifestação do fenômeno da seca. Ela é uma construção humana, passível, portanto, de ser revertida. é preciso romper com a imagem negativa em relação ao Semiárido, do sujeito que vive no Semiárido, que é visto como "matuto" ou como um "sujeito sem saber". O Semiárido é um território complexo e rico sobre o qual ainda pouco se conhece.

Conforme explicitado ascima, torna-se cada vez mais necessário buscarmos comprender que Região é essa e os seus potenciais, saindo de um olhar inviesado e cristalizado, construído sob estereótipos e que precisam ser ressignificados. Por isso, afirmamos que o Semiárido não é formado somente pela zona rural dos municípios. O Semiárido é vasto, e segundo a nova delimitação realizada, em novembro do ano de 2017, o Semiárido Brasileiro passou a ser composto por mais 73 Municípios, totalizando “[ [...] 1.262 municípios, dos estados do Maranhão, Piauí, Ceará, Rio Grande do Norte, Paraíba, Pernambuco, Alagoas, Sergipe, Bahia e Minas Gerais” (SUDENE, 2017, p.1).

Sendo assim, para um Município ser considerado pertencente ao Semiárido, o mesmo deve atender aos critérios estabelecidos pela Resolução $n^{\circ}$ 107/2017, sendo eles: "I Precipitação pluviométrica média anual igual ou inferior a $800 \mathrm{~mm}$; II - Índice de Aridez de Thorntwaite igual ou inferior a 0,50; III - Percentual diário de déficit hídrico igual ou superior a $60 \%$, considerando todos os dias do ano”.

Esses critérios são de extrema importância para a definição e redefinição constan te da área do Semiárido Brasileiro, pois, se antes o município para ser considerado pertencente a essa região bastava ter o índice pluviométrico igual ou inferior a $800 \mathrm{~mm}$, atualmente, só esse índice, não o caracteriza como tal, justamente por atentarem para o fato de que não é a falta de 
chuva que caracteriza essa região, e sim, a sua má distribuição e armazenamento. Além disso, evita-se também, o incessante interesse por parte dos municípios, em especial seus governantes, em querer receber políticas públicas específicas para essa região.Ou seja, "quero" ser integrante da região do semiárido no papel, nas resoluções, e não criar relações de pertencimento com essa região e o seu povo.

Diante desses elementos apresentados referentes a expansão da delimitação e os critérios que estabelecem um município ser ou não pertencente à Região Semiárida, questionamos: que Semiárido é esse, que mesmo tão grande, abrangendo tantos estados e municípios continua sendo “invisível” para o poder público? A única certeza que temos é a que os governantes continuam insistindo a negligenciar direitos básicos, entre eles, o acesso a Educação, e isso fica evidente no alarmante número de escolas do Campo extintas no ano de 2014, especialmente no Estado da Bahia, que aparece com 608 escolas fechadas (ROCHA; REIS, 2016). E, juntamente com esses dados, vem a tona uma série de problemas, entre eles a negligenciação do direito a educação na sua comunidade, como prevê o art. $3^{\circ}$, da Resolução n 02/2008: "a Educação Infantil e os anos iniciais do Ensino Fundamental serão sempre oferecidos nas próprias comunidades rurais, evitando-se os processos de nucleação de escolas e de deslocamento das crianças".

Não precisamos ir muito longe da nossa realidade para percebemos a negação desse direito estabelecido pela Resolução $\mathrm{CEB} / \mathrm{CNE} n^{\circ}$ 02/2008. É só observamos os municípios pertencentes ao Território do Sertão do São Francisco (TSSF), no norte do Estado da Bahia, para atentarmos para um fato: eles também estão negando o direito a Educação nas suas comunidades, às crianças/jovens e adultos do Campo. Entre os 10 municípios - sendo eles: Campo Alegre de Lurdes, Canudos, Casa Nova, Curaçá, Juazeiro, Pilão Arcado, Remanso, Sento-Sé e Sobradinho -, cinco deles fecharam escolas do campo no ano de 2014, totalizando 32 (trinta e duas) escolas extintas.

Diante dos dados trazidos, indagamos: para onde essas crianças são levadas? Que tipo de Educação é ofertada a elas? Por que isso vem acontecendo? Por que cortar gastos, e não garantir direitos? Que impacto a extinção dessas escolas causa nas crianças, nos pais e na comunidade? Para esses questionamentos, há respostas, há histórias, há tentativas de justificaticação. Se lermos um pouco que seja sobre a constituição histórica do campo, perceberemos, como aponta Reis (2011), um campo marcado por desigualdades, migrações e riquezas concentradas nas mãos de poucos, justamente pelos grandes latifundiários e grandes empresários que quererem expandir seus negócios, suas terras, exportarem seus produtos. E 
nessa ambição pelo lucro, quem não tem capital para manter suas terras, vai sendo "esmagado" pelo grande capitalismo, quando a única alternativa é vender suas terras, e ir trabalhar para os latifundiários, para ganhar uma pouquíssima remuneração econômica, ou tentar a sorte em outro estado ou município no qual acreditam ser mais fácil recomeçar a vida. Com isso, uma cena era constantemente contemplada e vivenciada por grande parte das famílias do Sertão Semiárido e do campo, como aponta Patativa Assaré (1989, p.90-91), em um de seus poemas:

Em riba do carro, se junta a famia;

Chegou o triste dia, já vai viajá.

A seca terrive, que tudo devora,

Lhe bota pra fora

Da terra natá.

O carro já corre o topo da serra.

Oiando pra terra, seu berço, seu lá,

Aquele nortista, partido de pena,

De longe inda acena:

Adeus, Ceará!

E assim vão deixando com choro e gemido,

Do berço querido,

O céu lindo e $a z u$.

Os pai pesaroso, nos fio pensando,

E o carro rodando, na estrada do Sul.

O que Assaré (1989) traz no seu poema são denúncias! Denuncia ausência de políticas públicas de convivência com a Região Semiárida, denuncia a falta de garantia de direitos básicos, como saúde, alimentação, educação para população, assim como, demonstra também o grande amor existente entre o povo que parte de sua terra, por ter que procurar garantias de um futuro melhor, por não ter acesso a esse direito no lugar em que vivia. Ou seja, até que ponto a invisibilidade do Estado interfere no modo de vida das pessoas, que são obrigadas a saírem de sua localidade, na ilusão de buscarem suprir suas necessidades em outras espaços, que na verdade são os seus direitos negligenciados.

A concepção da seca como problema tem influenciado e orientado a atuação de muitos governos na formulação, direcionamento e execução de políticas públicas que contribuíram para perpetuar e até agravar problemas ambientais, econômicos, sociais e políticos. É exatamente essa lógica que fundamenta o que se denomina de 'indústria da seca', com a compreensão de que é necessário combater a seca, sem problematizar e entender a semiaridez desde suas origens e as múltiplas formas de conviver com o Semiárido (CONTI, 2013, p.20).

Ao retratarmos essa realidade percebenos que a saída era o caminho primeiro para fugir do abandono. Aqui explicitamos outras inquietações: até quando? Até quando pessoas terão que sair de suas comunidades para tentarem ter acesso a direitos básicos? Até quando o lucro 
será concentrado nas mãos de poucos? Até quando as políticas públicas não chegarão ao Campo, e o mesmo será visto como lugar de atraso? Até quando milhares de crianças terão acesso, isso quando tem, a um ensino descontextualizado? Até quando?

$$
\text { Como nos alertamBaptista e Campos (2013, p.30), }
$$

a forte presença das políticas de combate à seca, com contribuição decisiva dos meios de comunicação social, construiu no imaginário popular uma falsa ideia sobre o Semiárido. Por isso, o Semiárido é descrito e apresentado como um lugar apenas de terra rachada e seca, onde se encontram carcaças de gado morto, crianças desnutridas e agricultura improdutiva. Portanto, o que era resultado da falta de estrutura e de políticas condizentes virou falta de água, e o que era a ausência do Estado, como provedor e promotor de políticas públicas adequadas, passou a ser compreendido como incapacidade do povo de inovar e criar alternativas para conviver com as condições de semiaridez da região (ASA, 2009)3. Nesse meio, a educação descontextualizada contribuiu e ainda contribui para a manutenção dessa situação. Através dela a escola inculca nas mentes das crianças a mentalidade de que na roça e no semiárido não há possibilidade de vida.

Acreditamos que para haver mudanças nas respostas dos questionamentos apontados acima, devemos, com urgência, descortinar a realidade que nos cerca. Temos que aprender a enxergar o campo, não mais como um espaço de atraso, como um lugar da "falta", em que as pessoas sãodoentes, pobres, magras,etc.. Não! Chega dessa visão, chega desse discurso hegemônico! Devemos atentar para o fato de que o campo é muito além de um espaço não rural, o campo abrange:

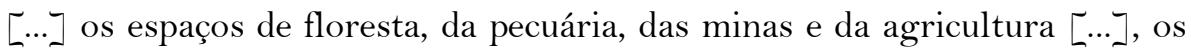
espaços pesqueiros, caiçaras, ribeirinhos e extrativistas. O campo, nesse sentido, mais do que perímetro não-urbano, é um campo de possibilidades que dinamizam a ligação do seres humanos com a própria produção de condições da existência social e com as realizações da sociedade humana, trazendo assim a incorporação dos sujeitos coletivos do campo no processo de desenvolvimento humano e sustentável do próprio campo. (REIS, 2011,p.56).

Como aponta Reis (2011), o campo abarca todos e os diversos espaços. O campo é um campo de possibilidades criadas pelas próprias pessoas que ali vivem. Não mais há espaço para imagens estereótipadas, de vegetação morta, chão rachado, falta de água, e uma Educação Descontextualizada. O que há, é um momento aberto para repensar essa realidade que insistem em manter e desvalorizar, uma vez que para se pensar o campo ou mesmo o Semiárido, ‘qualquer coisa serve', qualquer ensino basta. Por isso, não queremos mais um enisno dualista,

\footnotetext{
${ }^{3}$ ASA. Articulação do Semi-Árido. Construindo o futuro e cidadania no semiárido. ASA: Recife, 2009.
} 
nem tampouco uma educação rural, que não escuta as vozes dos protagonistas do espaço campo. O que queremos, e precisamos entender, é que:

enquanto a Educação do Campo vem sendo criada pelos povos do campo, a educação rural é resultado de um projeto criado para a população do campo, de modo que os paradigmas projetam distintos territórios. Duas diferenças básicas desses paradigmas são os espaços onde são construídos e seus protagonistas. Por essas razões é que afirmamos a Educação do Campo como um novo paradigma que vem sendo construído por esses grupos sociais e que rompe com o paradigma da educação rural, cuja referência é a do produtivismo, ou seja, o campo somente como lugar da produção de mercadorias e não como lugar de vida (FERNANDES, MOLINA, 2004,p.63)

Conforme Fernandes e Molina (2004) expressam, não mais queremos lutar somente pela garantia do direito à Educação do Campo. Não mais devemos nos acomodar com a negação de direitos, como a educação, e o fechamento das escolas. O que não queremos, em hipótese alguma, é a garantia desse direito de “qualquer jeito”, onde os projetos são elaborados dentro de gabinetes, sem levar em consideração as vozes dos sujeitos protoganistas do campo, impondo interesses e visões limitadas, em que para ser e viver no campo não necessita-se ir além do que aprender a escrever umas "palavrinhas” e fazer umas "continhas".

\footnotetext{
Além de ser lutador e forte, o povo do semiárido possui uma cultura de resistência contra as adversidades e as investidas dos meios de comunicação social para aniquilá-lo. O povo sertanejo se manifesta e resiste pelas danças e festas dos reisados, os sambas de roda, as toadas, os violeiros repentistas, a poesia de cordel, os fundos rotativos solidários, os bancos de sementes, os mutirões, as batas de feijão e milho, os bois roubados, as festas de São João, São Pedro e São José, a religiosidade (Padre Cícero, Bom Jesus da Lapa), as músicas e danças específicas, as comidas típicas, as bebidas e frutas, o modo de viver, lutar e amar (BAPTISTA; CAMPOS, 2013,p.31).
}

Não basta reconhecer a grandiosidade de um povo e continuar negando os seus direitos! Isso é muito comum nos discuros dos governantes. O que propomos é a garantia à educação, pois custo-benefício não justifica a violação de um direito que está previsto na Constituição Federal (1988). Mas, quando lutamos por essa garantia à educação no campo, lutamos por uma Educação do Campo, uma educação que leve em consideração a diversidade desse espaço, a realidade desse povo.

E quando lutamos insistetemente pela garantia e acesso à educação de qualidade no campo, nos apoiamos no artigo 28, da Lei de Diretrizes e Bases (1996), e nos seus incisos I, II, III, nos quais prevê: 
na oferta de educação básica para a população rural, os sistemas de ensino promoverão as adaptações necessárias à sua adequação às peculiaridades da vida rural e de cada região, especialmente: I - conteúdos curriculares e metodologias apropriadas às reais necessidades e interesses dos alunos da zona rural; II - organização escolar própria, incluindo adequação do calendário escolar às fases do ciclo agrícola e às condições climáticas; III adequação à natureza do trabalho na zona rural.

Esse artigo da LDB traz, de forma bem concisa, o que vínhamos discutindo: não dá para olhar para o campo e achar que aquele espaço não tem possibilidade de vida, não tem riqueza, não tem uma realidade específica, bem como povos com necessidades específicas. Por isso, torna-se inadmissível ainda pensar atualmente em uma educação rural para o campo, por exemplo, pois ela não mais - na verdade nunca - serviu para a emancipação integral da população campesina, pelo contrário, aumentavao repúdio à escola, por não se reconhecerem naquele espaço.

E tal realidade vem sendo modificada, justamente, por a população não mais aceitar essa educação excludente, pois como evidencia Arroyo (2004,p.73) "os homens e mulheres do campo [...] se reconhecem sujeito de direitos”. E ao se reconhecerem como tal, não aceitam “qualquer coisa”, qualquer educação, e muito menos, negação aos seus direitos. Por isso, passam a perceber que a escola que está posta, não serve. É uma escola que faz adaptação dos currículos da zona urbana, para garantir a sonhada 'educação igualitária', e negar todo o conhecimento, vivência e realidade daqueles que a compõem. Não enxerga o aluno como“ “[...] gente, no seu tempo, na sua idade, no seu gênero, na sua raça, na sua história, na sua diversidade, no seu momento de formação humana [...](ARROYO, 2004, p.75). Por este motivo, tende a desprezar o contexto em que a população está inserida, logo, a urgência de repensar essa escola, esse currículo. Portanto, ainda há a necessidade de se

fazer Educação Contextualizada [...] que parta da realidade dos sujeitos; parta da riqueza, dos limites e da problemática geral dos contextos de vida das pessoas. Mas, não é para ficar dando voltas nisto. É para produzir conhecimento sofisticado, baseado em trabalhos de pesquisa, em estudos, em tematizações, em problematizações fundamentadas e em ações concretas, amparadas pelos conhecimentos gerados num itinerário pedagógico, partindo sempre da teoria à prática e vice-versa [...] (MARTINS, 2011, p.58).

Desse modo, como propõe Martins (2011), a Educação não se faz fora do ambiente e dos conhecimentos em que a população está inserida, afinal, a mesma não é uma ilha deserta, e sim um processo pertencente à Sociedade, e que por conta disto, por si só, já está enraizada nas temáticas que fazem parte de uma comunidade. Assim, não há mais espaço para uma 
educação que force os alunos a se despirem deles mesmos, para aprenderem o que a escola tem a ensinar. Não há espaço para uma educação que não tenha a 'cara', a cor e movimento dessas crianças, jovens/adultos do Campo. Pois, como questiona Alves (1994, p.14): “[ [... poderá haver sofrimento maior para uma criança ou um adolescente que ser forçado a mover-se numa floresta de informações que ele não consegue compreender, e que nenhuma relação parecem ter com sua vida?”.É exatamente assim que a população do campo se sente ao ir para a escola que nega sua realidade; se sente perdida, desestimulada, é como se a escola falasse uma outra língua, língua esta que não dialoga com o seu contexto, e por isso, o depreza, o exclui.

É necessário repensar não somente como a educação vem sendo oferecida no campo, mas refletir sobre: Que sujeitos queremos formar com a educação que está sendo desenvolvida? Não queremos que a população do Campo tenha somente acesso a escola nas suas comunidades, queremos também uma educação de qualidade, que vise a formação integral do ser humano, estimulando seu senso crítico para conhecer, perceber e transformar sua realidade, englobando para isso, o contexto bem mais amplo, o global. Pois, peca quem pensa que trabalhar Educação Contextualizada é trabalhar em volta de um círculo vicioso que gira somente em torno de uma comunidade, uma cidade, um estado. O conhecimento parte do contexto local, mas não prende-se a ele, justamente pelo mesmo não ter limites, e estar dialogando constantemente com essa teia de relações - Comunidade, Município, Estado e País.Essa deveria ser uma das preocupações na construção coletiva do Projeto PolíticoPedagógico (PPP) das escolas do campo por parte dos sistemas educativos. Mas, como o PPP é apenas um intento presente nos marcos legais, quando deveria ser elemento fundamental à existência de uma unidade escolar, pois representa a bússola que deveria nortear a proposta pedagógica da escola e os seus valores éticos.

O que se constata na análise dos dados oficiais que incluem os municípios do Territórios do Sertão do São Francisco (TSSF), assim como em outras localidades do país, é que o poder público tem atentado o tempo todo contra o direito à educação, quando fecha uma escola do/no campo, mesmo com a existência da Lei 12.960, de 27 de março de 2014, que altera a atual LDB, criando possibilidades de dificultar o fechamento de escolas do campo, indígenas e quilombolas. Essa Lei obriga a exigência de manifestação de órgãos normativos como os Conselhos Municipais de Educação, no âmbito municipal e no âmbito estadual, quando do fechamento de escolas como as citadas anteriomente, ouvindo a comunidade e com ela deliberando favorável ou não sobre essa medida. Uma pena, pois na maioria das vezes, as Secretarias de Educação já chegam com a ata do fechamento pronta. 


\section{Escolas do campo extintas no Semiárido Brasileiro}

O levantamento da quantidade de Escolas do Campo extintas no Semiárido Brasileiro em 2014, foi realizado tendo como paraâmetro da delimitação do Semiárido realizada pelo Governo Federal, em 2005. Portanto, foram pesquisados os municípios que pertencem aos seguintes Estados: Alagoas, Bahia, Ceará, Minas Gerais, Paraíba, Pernambuco, Piauí, Rio Grande do Norte, e Sergipe, considerados pertencentes à Região do Semiárido Brasieliro de acordo com os critérios discutidos anteriormente.

O gráfico 1 demonstra os Estados do Semiárido Brasileiro que mais fecharam Escolas do Campo, no ano de 2014.

\section{Gráfico 1}

Quantidade de escolas do campo fechadas nos Estados do Nordeste no ano de 2014

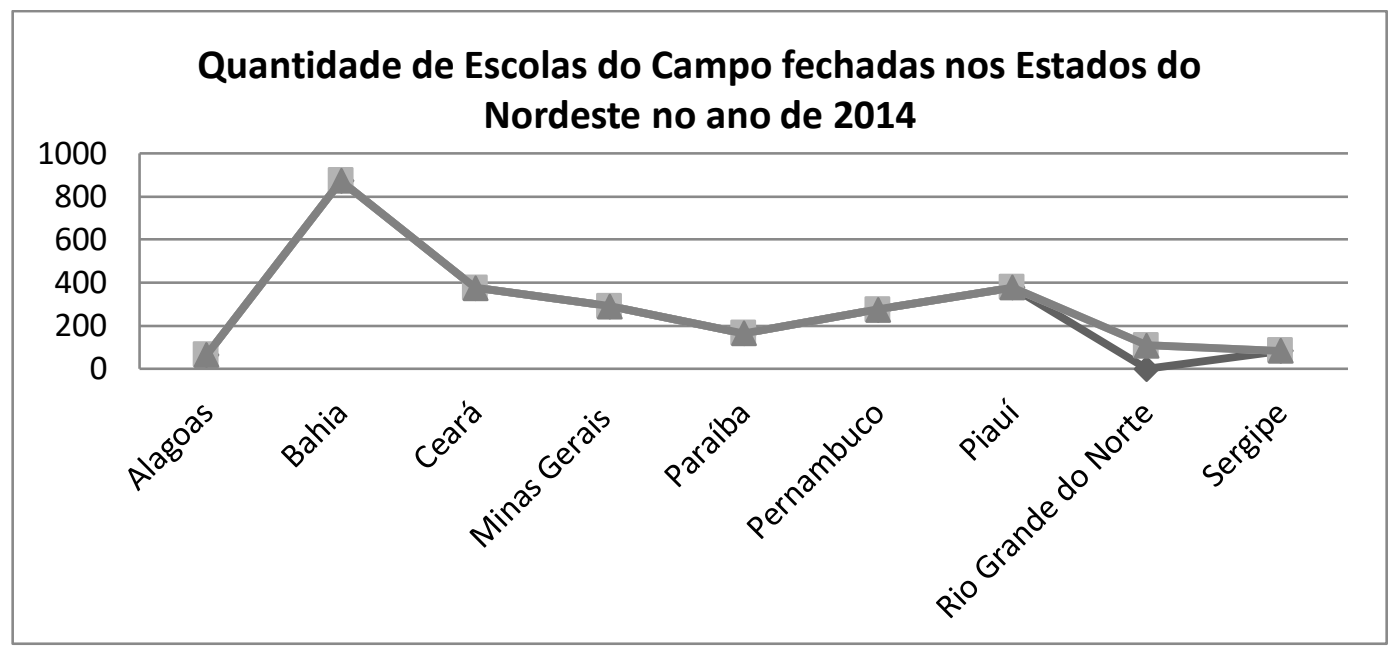

Fonte: MST Elaboração: Projeto Reflexão dos Referenciais da Educação Contextualizada (2015).

Através dos dados dispostos no gráfico acima, pode-se perceber que o Estado do Nordeste que mais fechou escolas do campo no ano de 2014, foi a Bahia, com 872 escolas extintas. O gráfico 2 demonstra os Estados do Semiárido que mais fecharam Escolas do Campo no ano de 2014. 
Gráfico 2

Estados do Semiárido Brasileiro que mais fecharam escolas no campo em 2014

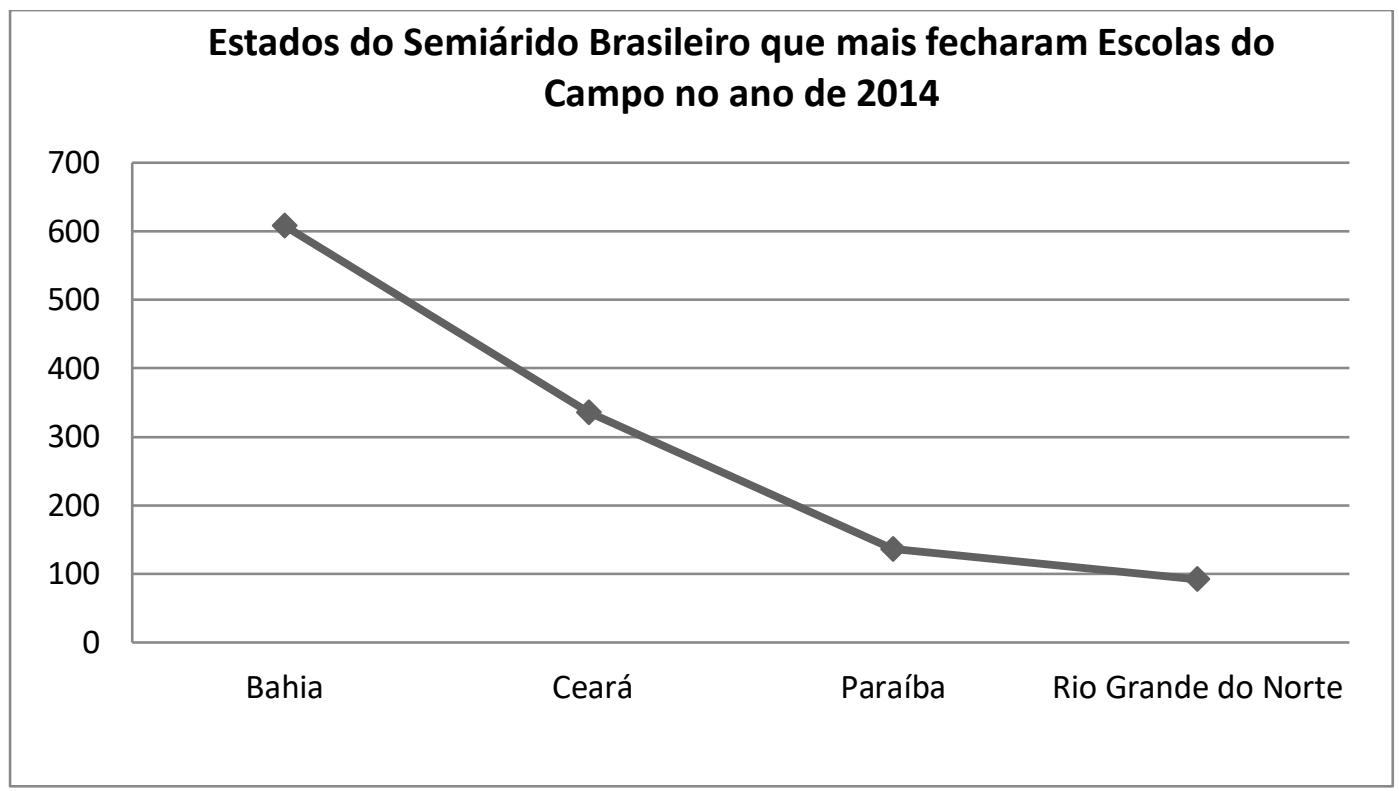

Fonte: MST Elaboração: Projeto Reflexão dos Referenciais da Educação Contextualizada (2015).

Segundo os dados do gráfico 02, pode-se constatar que os Estados da Bahia, Ceará Paraíba, e Rio Grande do Norte possuem números alarmantes em relação à quantidade de escolas do Campo que foram fechadas somente no ano de 2014. Pode-se observar ainda que essa quantidade de Escolas que vêm sendo extintas traz à tona uma série de problemas, entre eles a negação do direito a educação a essas crianças do campo, pois se deixa de cumprir o que a Resolução nº 02/2008 estabelece nas Diretrizes Complementares, no seu artigo $3^{\circ}$, já citada neste texto: "a educação infantil e os anos iniciais do ensino fundamental serão sempre oferecidos nas próprias comunidades rurais, evitando-se os processos de nuclearização de escolas e o deslocamento das crianças", assim como se descumpre a Lei 12.960, de 27 de março de 2014, que trata das normas para fechamento de escolas no campo.

Quando se fecham as instituições escolares do campo, além de descumprir os marcos legais, muitas crianças deixam de frequentar a escola, porque, na maioria das vezes, são transferidas para a zona urbana acarretando na superlotação das escolas, comprometendo a aprendizagem e as relações de convivência, bem como, aumentam-se as taxas de evasão, pois Nem todos os pais confiam em mandá-las nos transportes escolares disponibilizados pelas prefeituras, por serem muito precários, e não oferecerem segurança às crianças durante o trajeto percorrido para chegar a escola. Além disso, quando transferidas para estudar na cidade, as crianças acabam perdendo sua referência de identidade do campo, pois são inseridas 
em uma cultura que considera o campo como um lugar de atraso, sendo desmotivados pela distância, discriminação e pela descontex tualização dos conteúdos e informações, passando-se, assim, a negar mais um direito da criança do Campo, previsto na $\operatorname{LDB} \mathrm{n}^{\circ}$ 9.394,20 de Dezembro de 1996, de ter uma escola com currículo voltado para a realidade das comunidades do campo.

É evidente que quando as Escolas do Campo são extintas, e as crianças são transferidas para a zona urbana, torna-se muito difícil trabalhar com a proposta do artigo 28 LDB1996, pois a realidade do campo e da cidade é bastante divergente, o que acarreta na descontextualização de currículo, conteúdo, realidade e materiais didáticos, levando aos alunos a se perguntarem: “o que estou fazendo aqui?”; e a pensarem: “esses conteúdos vistos na escola não servem para nada, pois não preciso deles para executar minhas atividades na roça”. Essa desterritorialização do aluno do campo muitas vezes o levará ao abandono dos estudos. É importante ressaltar, mais uma vez, que a defesa pela contextualização aqui feita, não quer dizer que o aluno fique restrito a conteúdos do campo, nem foi uma crítica negativa à maneira que a escola da zona urbana trabalha pedagogicamente. Porém, estamos tratando dos direitos das crianças do campo, previstos na legislação, e que com a ex tinção das escolas do campo em 2014, acarretou e acarreta uma série de problemas para a educação dessa população, dentre eles, a negação de estudar próximo de sua casa, e uma educação de qualidade e contextualizada como prevê o art.28 da Lei de Diretrizes e Bases.

\section{Escolas do campo extintas nos municípios do Território do Sertão do São Francisco (Norte da Bahia)}

Tendo como objetivo geral refletir sobre os limites e processos de extinção das escolas do campo no Semiárido Brasileiro, iremos expor os reais motivos que acarretaram a extinção dessas escolas. De acordo com o Censo Escolar de 2014 (MEC/INEP), somente no Semiárido Nordestino foram extintas 4.084 escolas, diante disso, optamos por pesquisarmos municípios que compõe o Território do São Francisco, sendo eles: Campo Alegre de Lourdes, Canudos, Casa Nova, Curaçá, Juazeiro, Pilão Arcado, Remanso, Sento Sé, Sobradinho e Uauá, por serem mais próximos do nosso local de origem, como demonstra o gráfico 3: 


\section{Gráfico 3}

Quantidade de escolas do campo fechadas nos municípios do Território do Sertão do São Francisco, no ano de 2014.

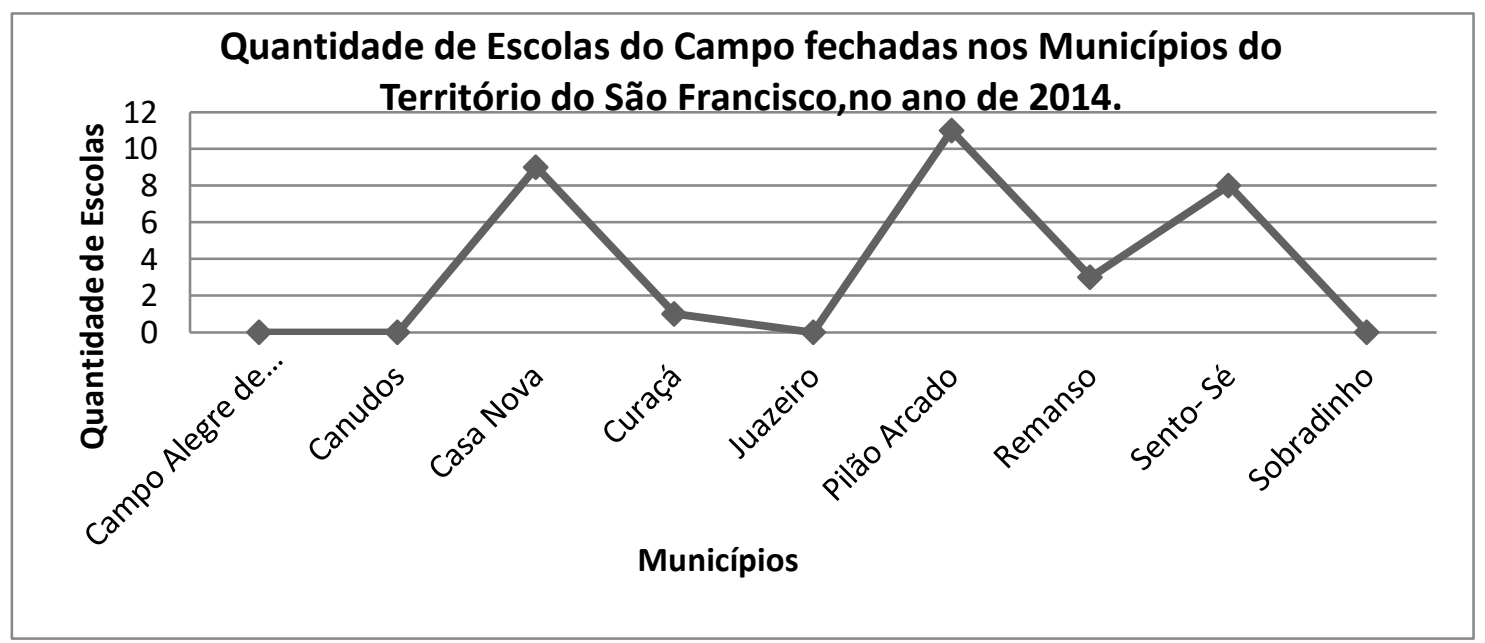

Fonte: MST Elaboração: Projeto Reflexão dos Referenciais da Educação Contextualizada (2015).

Segundo os dados desse gráfico, os municípios que mais se destacam com o fechamento de escolas do campo, ano de 2014, são: Casa Nova, Pilão Arcado e Sento-Sé. Já os municípios que não fecharam nenhuma escola no ano de 2014, foram: Campo Alegre de Lourdes, Juazeiro e Sobradinho. Dessa forma, procuramos entrar em contato, através de email eletrônico e telefone com as Secretárias de Educação dos municípios que fecharam escola no ano de 2014, para procurarmos saber quais foram os motivos que instigaram a extinção dessas escolas.

Dessa forma, só obtivemos resposta do município de Curaçá-BA, onde foi fechada somente uma Escola do Campo, como mostrada no gráfico 3, a Escola Municipal Ararinha Azul, que segundo as informações obtidas foi extinta pelo baixo número de alunos matriculados na localidade, como fica evidente na seguinte passagem:

a Escola Municipal Ararinha Azul ficava na Fazenda Pau de Colher e foi fechada em 2014. O motivo do fechamento foi o baixo número de alunos na localidade. Em 2013, tinham 11 alunos do pré-escolar ao $5^{\circ}$ ano, sendo apenas 2 residentes na Fazenda e 9 eram transportados.Diante de uma turma multisseriada do pré ao $5^{\circ}$ ano, com os custos cada vez maiores para manter a escola funcionando, a Secretaria de Educação resolveu transportar todos os alunos para o Povoado de São Bento, onde os alunos não ficariam em turmas multisseriadas com tanta diferença de idade. Essa foi a visão da Secretária de Educação,que na época, achou mais viável, tanto do ponto de vista pedagógico como no custo-benefício (INFORMANTE 1, 2015). 
De acordo com a Resoluçãonº 02, de 28 de Abril de 2008, os alunos só podem ser transferidos para estudar em outra localidade:

art. $4^{\mathrm{o}}$ quando os anos iniciais do Ensino Fundamental não puderem ser
oferecidos nas próprias comunidades das crianças, a nucleação rural levará
em conta a participação das comunidades interessadas na definição do local,
bem como as possibilidades de percurso a pé pelos alunos na menor distância
a ser percorrida. Parágrafo único. Quando se fizer necessária a adoção do
transporte escolar, devem ser considerados o menor tempo possível no
percurso residência-escola e a garantia de transporte das crianças do campo
para o campo.

Dessa forma, fica evidente que para o fechamento de Escolas no Campo, mas especificamente no caso de Curaçá-BA, a comunidade teria que ter conhecimento dos motivos que acarretaram o fechamento da instituição, bem como, todo o processo de escolha para onde seriam levadas essas crianças. Além disso, a escolha do local deve favorecer a localidade da criança, ou seja, as mesmas devem ser transportadas do campo para o campo, de modo que o seu bem estar seja garantido. E dependendo da distância, os transportes para a locomoção devem ser oferecidos pelos entes Municipais. No caso de Curaçá-BA, não fomos informados da distância que os alunos percorrem diariamente para ter acesso a escola, nem se os mesmos são transportados em transportes escolares oferecidos pela Prefeitura. Porém, é válido ressaltar que o fechamento de escolas é crime por se tratar de uma violação de direitos ao presente e futuro de milhares de crianças do campo.

Apesar das justificativas, como no caso de Curaçá-BA, de que havia muitos gastos para se manter a escola funcionando, enquanto o número de alunos era muito pequeno, embora saibamos que o número de estudantes não garante a manutenção da escola, mas sim a união e força comunitária, vale destacar, porém, que para se fechar escolas, é necessário que as justificativas sejam coerentes e aceitas pela comunidade, ede acordo com aa leis que regem a educação, bem como que as alternativas sejam cabíveis, aceitas e regulamentadas de acordo com a lei, proporcionado um ensino-aprendizagem de qualidade para os alunos do campo.

Faz-se necessário em meio a essa discussão dos motivos que acarretam o fechamento das Escolas do Campo, destacar que a comunidade pode impedir a ex tinção da mesma, quando considera que os motivos apresentados não são relevantes para tal processo. Sendo assim, é importante que a comunidade esteja atenta ao que ocorre dentro da instituição escolar, bem como se reúna, convide órgãos da imprensa, universidades próximas, lideranças dos movimentos sociais, e Conselho Municipal de Educação para que, em uma assembleia, possam construir uma ata que justifique a continuidade ou o fechamentos da escola, bem como um 
abaixo assinado, sendo que todos os documentos comprobatórios devem ser assinados por todos.

Em sequência, é preciso que se organize uma comissão que fique responsável por encaminhar os documentos ao Ministério Público, para que a denúncia seja oficializada, bem como solicitar reuniões com a Promotoria Pública para efetivá-la pessoalmente, e, além disso, deve-se reunir-se também com vereadores, Secretária de Educação, com a cópia dos documentos assinados e protocolados, para que se solicite a revisão do fechamento de determinada Escola.

Sendo assim, torna-se evidente o importante papel que a comunidade exerce para o não fechamento das escolas do campo. É essencial, que se lute, e adote a campanha que diz não ao fechamento de mais escolas do campo na Região do Semiárido, pois se faz primordial que se cumpra os direitos estabelecidos pela LDB 9394/96, Resoluções CNE/CEB nº 01/2002 e n ${ }^{\circ}$ 02/2008 e Lei 12.960, de 27 de março de 2014, entre outras leis que regulamentam a educação brasileira para que as crianças do campo e do Semiárido tenham acesso a uma educação de qualidade, que contribua para a formação de um cidadão crítico, estabelecendo condições favoráveis que contemplem os seus direitos, até então esquecidos. Dessa forma, diga não ao fechamento das escolas do campo.

\section{Considerações finais}

Diante dos dados trazidos e discutidos ao longo deste artigo, conclui-se que o número da quantidade de Escolas do Campo extintas no ano de 2014 são altíssimos, especialmente na Bahia, tornando-se obvio a negação do direito à educação a essas crianças que fazem parte da Região do Semiárido Brasileiro, previsto na Resolução nº2, de 28 de Abril de 2008, no seu artigo $1^{\circ}$, inciso $\S 1^{\circ}$, quando responsabiliza os Entes Federados pelo planejamento, execução e universalização o acesso à educação básica pública.

Sendo assim, o presente artigo busca contribuir com a divulgação e discussão desses dados que muitas vezes não são apresentados ou tornam-se esquecidos pela sociedade, para que as escolas do campo deixem de ser extintas, e a população passe a lutar pelos seus direitos, assim como as crianças tenham garantido o acesso a uma educação de qualidade que contribua para sua formação crítica enquanto cidadão.

Enquanto for apenas a relação custo-benefício o que se leva em consideração na definição do fechamento das escolas do campo, estaremos afirmando cada vez mais a exclusão 
dos povos do campo ao direito de ter a educação do e no campo, além de que muitas vezes, a escola é a única forma de manifestação do Estado em uma comunidade do campo, quando o fechamento torna-se a evidencia do seu modo de compreender a relação do Estado no campo, o da indiferença.

Enquanto sociedade, enquanto professores e pesquisadores comprometidos com a educação pública é importante contiunuarmos atentos e sempre vigilantes, para que a partir das informações colhidas e constatadas, essas possam servir de base para pressionar o poder público a cumprir o seu papel, na garantia do direito à educação, algo fundamental na mudança dos destinos de uma nação e no caso específico da Educação do Campo, um instrumento de luta e de afirmação da diferença dos povos do campo, como cidadãos de direitos que precisam ser respeitados.

No âmbito do Grupo de Pesquisa em Educação Contextualizada, Cultura e Território (EDUCERE) esta tem sido uma preocupação da qual não abrimos mão, pois compreendemos a academia, o ensino, a pesquisa e a extensão como espaços retoalimentados e que se fazem com base na informação cuja fonte é a sociedade e que, para tanto,essas mesmas informações precisam se constituir em possibilidades de reinvenção dessa própria sociedade, muitas vezes marcada por estigmas, preconceitos e determinações de cima para baixo, sem que as comunidades sejam ouvidas, como por muito tempo foi feito com o campo e com o Semiárido Brasileiro. Mais do que nunca, o respeito à diferenças deve ser a base da constituição do direito e da afirmação das políticas públicas.

\section{Referências}

ALVES, Rubem. A alegria de ensinar. 3.ed. São Paulo: Ars Poética, 1994.

ARROYO, Miguel Gonzalez. A Educação Básica e o Movimento Social do Campo. In: ARROYO, Miguel Gonzalez; CALDART, Roseli Salete; MOLINA, Mônica Castagna (Org.). Por uma educação do campo. Petrópolis: Vozes, 2004. p.65-86.

ASSARÉ, Patativa. Cante lá que eu canto cá. Petrópolis: Vozes, 1989.

BAPTISTA, Naidison de Quintella; CAMPOS, Carlos Humberto. Fatores históricos, sociais, culturais e políticos do Semiárido. In: CONTI, Irio Luiz; SCHROEDER, Edni Oscar (Org.). Estratégias de Convivência com o Semiárido Brasileiro: Textos e Artigos de Alunos(as) Participantes. Brasília: IABS, 2013.

BRASIL. Censo Escolar 2014. Brasília: MEC/INEP, 2015. 
Constituição da República Federativa do Brasil. Brasília: Supremo Tribunal Federal, Secretaria de Documentação, 2017.

Lei de Diretrizes e Bases da Educação de 1996. Disponível em: <http://www2.senado.leg.br/bdsf/bitstream/handle/id/529732/lei_de_diretrizes_e_bases_ 1ed.pdf>. Acessado em: 18 de Abril de 2018.

Lei 12.960, de 27 de março de 2014. Brasília: Presidência da República, 2014.

.Resolução $n^{o}$ 02, de 28 de Abril de 2008. Disponível em: <portal.mec.gov.br/arquivos/pdf/resolucao_2.pdf>. Acessado em: 15 de Abril de 2018.

Resolução $\quad n^{\circ} \quad$ 107/2017. Disponível em:

<http://sudene.gov.br/images/2017/arquivos/Resolucao-107-2017.pdf>. Acessado em: 18 de Abril de 2018.

CONTI, Irio Luiz. Introdução. In: CONTI, Irio Luiz; SCHROEDER, Edni Oscar (Orgs). Estratégias de Convivência com o Semiárido Brasileiro: Textos e Artigos de Alunos(as) Participantes. Brasília: IABS, 2013.

FERNANDES, Bernardo Mançano; MOLINA, Mônica Castagna. O campo da Educação do Campo.In: MOLINA, Mônica Castagna ; AZEVEDO DE JESUS, Sônia Meire Santos (Org.).Por uma Educação do Campo: Contribuições para a construção de um projeto de Educação do Campo. Caderno nº 05.Brasília:Articulação Nacional por uma Educação do Campo, 2004.

GIL, Antonio Carlos. Como elaborar projetos de pesquisa. 4.ed. São Paulo: Atlas, 2002.

MARTINS, Josemar. Educação Contextualizada: Da teoria à prática. In: REIS, Edmerson dos Santos; CARVAlHO, LuzineideDourado(Org.). Educação Contextualizada: Fundamentos e Práticas. UNEB/ Departamento de Ciências Humanas - Campus III/ UNEB/NEPEC-SAB/ $\mathrm{MTC} / \mathrm{CNPq} / \mathrm{INSA}$. Juazeiro, 2011. p.45-64.

REIS, Edmerson dos Santos. Educação do Campo: escola, currículo e contexto. Juazeiro:ADAC/ UNEB-DCH-III/ NEPEC-SAB, 2011.

ROCHA, Adma Hermenegildo Rocha; REIS, Edmerson dos Santos Reis. O fechamento de escolas do Campo no Território do São Francisco, Semiárido Baiano. Caderno Multidisciplinar Educação e Contexto do Semiárido Brasileiro-Múltiplos Olhares sobre a Educação no Semiárido Brasileiro.Ano 10, nº 08, Dezembro de 2017. Juazeiro: Selo Editorial Resab, 2016, p.87-103.

SUDENE. Superintendência do Desenvolvimento do Nordeste. Disponível em: $<$ http://sudene.gov.br/planejamento-regional/delimitacao-do-semiarido>. Acessado em: < 18 de Abril de 2018. 